\title{
Efficacy of some plant extracts against Tetranychus urticae Koch (Acari: Tetranychidae) on cucumber and kidney bean crops under laboratory and field conditions
}

\author{
Mohamed A. S. M. ${ }^{*}$, Abdel-Samad M. A. ${ }^{1}$, Abouelkassem Sh. ${ }^{2}$, AbouShosha M. A. A. ${ }^{1}$ \\ ${ }^{I}$ Department of Agricultural Zoology and Nematology, Faculty of Agriculture, Al-Azhar University, Assiut, Egypt \\ ${ }^{2}$ Plant Protection Department, Faculty of Agriculture, Al-Azhar University, Assiut, Egypt
}

\begin{abstract}
In the laboratory and field experiments carried out to investigate the efficiency of some acetone and methanol plant extracts, against Tetranychus urticae Koch on kidney bean and cucumber plants. The results were recorded after 3 days for laboratory treatment. The obtained data indicated that, the acetone Egyptian henbane extract was the high toxic to the females of $T$. urticae with mortality rate $91.21 \%$, followed by methanol thorn apple extract with mortality rate $85.71 \%$, acetone winter cherry extract with mortality rate $83.52 \%$, and methanol neem extract with mortality rate $75.82 \%$. While common milkweed and sweet clover extract gave a weak mortality rate when extracted by both solvents. However, in the field experiment the plant extracts which extracted by methanol at a concentration $4 \%$, recorded a high reduction at rang of $(67.95-79.47 \%)$ on kidney bean while, on cucumber was between (74.51-80.16\%). These results suggest that plant extracts could be incorporated in integrated pest management (IPM) programs of T. urticae on Kidney bean and cucumber plants.
\end{abstract}

Keywords: Tetranychus urticae, Hyoscyamus muticus, Datura stramonium, plant extracts. 


\section{Introduction}

Tetranychid mites contains many serious species that are important pests of several economic crops; Spider mites are the most lethality mites belonging to family Tetranychidae and common pest of many crops, they feed on more than 180 plant species in greenhouse and field (Chakraborty et al., 2009). Very heavy losses in crops as beans, cotton, pears, plums and many other horticultural and ornamental crops are caused by spider mite infestation (Rabbinge, 1985). Many vegetable crops such as tomatoes, squash, eggplant, and cucumber are also infested by two spotted spider mite (Fasulo and Denmark, 2000). The two-spotted spider mite has been recognized as serious pests to more than a host plant of economic important (Jeppson et al., 1975). Spider mites cause serious economic damages to vegetable corps by feeding on foliage, squeezer reduce photosynthesis, transpiration, leaf chlorophyll content, leaf nitrogen and increase transpiration (Guo et al., 1998). These pests are generally controlling by synthetic acaricides. Synthetic pesticides are effective in the control of mites. However, use of such compounds has a number of disadvantages such high cost, toxicity to natural enemies, adverse environmental impacts, health and safety hazards to the growers and development of resistant in population of mites (Norval et al., 1992). A new approach in pest control such as the use of natural plants products must receive considerable attention; For instance, the methanol extract of Cleome gynandra, Capsicum frutescence and Urtica dioica were highly reduced Tetranychus urticae populations (Kapsoot et al., 2013). Essential oils are another group of plant products that, has been tested for their acaricidal activity. Essential oils extracted from aromatic plants, they have diverse effects on insect pests, since they have repellent, insecticidal, anti-feeding, growth inhibitor, oviposition inhibitor, ovicidal, and growth-reducing effects on a variety of insects (Hikal et al., 2017). Plant derivatives comprise a diverse group of compounds such as nicotine and pyrethum which probably serve a defensive function against herbivores in the plant of origin. Cremlyn, (1978), showed that, plants which have been shown to have acaricidal constituents include tobacco, comphor and derrises which were in use before organized searches for began as insecticides. The aim of the present work is to study the effect of some plant extracts as an alternative to chemical control on $T$. urticae in laboratory and field.

\section{Materials and methods}

\subsection{Rearing of T. urticae}

T. urticae was collected from eggplant at farm of Faculty of Agriculture Al-Azhar University, Assiut, Egypt. Apure culture of T.urticae maintained on kidney bean leaf placed in petri dishes on moisturized cotton under laboratory condition $\left(25 \pm 1 \mathrm{C}^{\mathrm{o}}\right.$ and $70 \pm 5 \%$ Relative humidity). Kidney bean plants (Phaseolus vulgaris L.) planted in pots $(25 \mathrm{~cm}$ diameter) in sunny place. When the kidney bean plants reached about six to 8 leaves 
contaminated with two- spotted spider mites from the pure culture as a source.

\subsection{Plants and preparation of extracts}

Six plant species demonstrators in Table (1) were covered in this study. The leaf and flower were collected from the forests, Faculty of Agriculture Al-Azhar University, Assiut, Egypt. Five hundred grams of plants were dried in shade at room temperature for two weeks and grindered using an electric blender homogenized to fine powder and stored in screw tight jar until use 200-gram powdered sample from each plant was charged into Soxhlet apparatus and Acetone and Methanol successively. Each time before employing the solvent of higher polarity sample was dried.

Table (1): The plants used in the experiments.

\begin{tabular}{|l|l|l|}
\hline English name & Scientific name & used part \\
\hline Winter cherry & Withania somnifera L. & Leaves \\
\hline Neem & Azadirachta indica A.Juss & Leaves \\
\hline Thorn apple & Datura stramonium L. & Leaves \\
\hline Common milkweed & Asclepias fruticosa L. & Leaves \\
\hline Sweet clover & Melilotus albus Desr & Leaves \\
\hline Egyptian henbane & Hyoscyamus muticus L. & Flower \\
\hline
\end{tabular}

2.3 Effect of plant extracts on adult females of $T$. urticae and treatment design

Ten newly emerged adult females were transferred to the upper surface of Kidney beans leaf discs ( $3 \mathrm{~cm}$ diameter). Leaf disc was kept on moist cotton ped in petri dish $10 \mathrm{~cm}$ diameter; each treatment was ten replicated times. Each dish was sprayed with one of following concentration $(0.5 \%, 1 \%, 2 \%$, and $4 \%)$ plus untreated control by a manual atomizer and the dishes were left at room temperatures at $27 \pm 2{ }^{\circ} \mathrm{C}$ and $65 \pm 5 \% \mathrm{RH}$. The untreated control was sprayed by water and additive solvent dimethyl salphoccied (DAMSO) by rate $(0.1 \%)$. $T$. urticae mortality was recorded 1, 2 and 3 days after treatment with a binocular microscope. A spider mite was considered dead if it was incapable of coordinated forward movement.

\subsection{Effect of plant extracts on eggs of $T$. urticae}

Ten newly adult females were transferred to upper surface of kidney bean discs (3 $\mathrm{cm}$ diameter) kept on moist cotton ped in each petri-dish $(10 \mathrm{~cm}$ diameter $)$, each dish was replicated five time and left 24 hours to deposited egg. The number of eggs was adjusted to 40 by removing or adding eggs with a fine camel hairbrush, the disk surface which carrying the eggs was separately sprayed with plant extracts using a manual atomizer and dishes were kept in incubator at temperatures $25 \pm 1{ }^{\circ} \mathrm{C}$ and $70 \pm 5 \% \mathrm{RH}$. 
The untreated control was sprayed with water and additive solvent (DMSO) by rate $(0.1 \%)$. Hatching and inhibition percent was calculated after 6 days from treatment, according to Abbott's, formula (1925):

Reduction $(\%)=1-\frac{\text { Treatment after }- \text { control before }}{\text { Treatment before }- \text { control after }} \times 100$

\subsection{Field efficacy of plant extracts on $T$. urticae}

Field trials were conducted at the farm, Faculty of Agriculture Al-Azhar University, Assiut, Egypt on March-May 2019. Natural T. urticae infestation was used to evaluate the efficacy of plant extracts at concentration $4 \%$ for each extraction from previous extracts on cucumber (Hail variety) and kidney bean (Hail variety), units comprised three plots each measuring $11 \mathrm{~m} \times 25 \mathrm{~m}$ four treatments and another two as a control. A randomized block design with three replicates was used for experiment. During application of extracts the whole plants were thoroughly covered by spray fluid and care was taken to maintain the distance around $25 \mathrm{~cm}$ between the nozzles and plant parts, treatments were applied by knapsack sprayer furnished with one nozzle boom. A total of 30 leaves from 3 replicates were collected from each cucumber and kidney bean. The leaves taken from each plant were put in paper bag, and then transported to the laboratory at Zoology and Nematology Department Faculty of Agriculture Al-Azhar University, Assiut,
Egypt. The numbers of $T$. urticae populations (mobile stages) were counted before and after spraying by binocular from upper and lower surface of 10 leaves from each plot in three replicates. The samples were collected after spraying with intervals $1,3,7,14$ and 21 days; The reduction percentages were calculated according to Abbott's, formula (1925).

\subsection{Statistical analysis}

Obtained data was subjected to one way analysis of variance (ANOVA) followed by F-test according to procedures by IBM SPSS statistics for windows, (version 20, 2011) and M.S. mean square, and the values were compered at $5 \%$ level tests. Means were separated by Duncan's multiple range test (DMRT).

\section{Results}

\subsection{Effect of plant extracts on T. urticae adult females in laboratory}

Data in Table (2) show that, the mortality percentages of $T$. urticae adult females who caused by plant extracts which extracted by acetone and methanol solvents were differed according to the extraction method for the acetone solvent, the extracts recorded significant differences, so the mortality rates were $91.21,84.62,78.02,69.23,53.85$ and $13.18 \%$ at $4 \%$ concentration for Egyptian henbane, thorn apple, winter 
cherry, neem, common milkweed and sweet clover after three days of exposure respectively. While for the methanol solvent plant extracts, the mortality rates at the $4 \%$ concentration were as follows $85.71,83.52,75.82,73.63,49.96$ and $46.15 \%$ for thorn apple, winter cherry, neem, Egyptian henbane, common milkweed and sweet clover at the same exposure respectively. While the mean mortalities for the four concentrations of the extracts were $64.84,59.34,55.22$, $50.55,43.13$ and $8.24 \%$ for Egyptian henbane, thorn apple, winter cherry, neem, common milkweed and sweet clover respectively, when extracted by acetone solvent and $(63.73,62.36,54.66$, $46.97,53.99$ and $29.11 \%$ ) after three days for treatment for winter cherry, thorn apple, neem Egyptian henbane, common milkweed and sweet clover when extracted by methanol solvent.

Table (2): Mean of mortality percentages of T. urticae adult females by $0.5,1,2$ and $4 \%$ concentrations of plant extracts extracted by acetone and methanol solvents after 3 days under laboratory condition.

\begin{tabular}{|c|c|c|c|c|c|}
\hline \multirow{3}{*}{ Plant extracts } & \multirow{3}{*}{ Concentration $(\%)$} & \multicolumn{4}{|c|}{ Mean of mortality\% with different solvents } \\
\hline & & \multicolumn{2}{|c|}{ Acetone } & \multicolumn{2}{|c|}{ Methanol } \\
\hline & & Mortality & Mean & Mortality & Mean \\
\hline \multirow{4}{*}{ Winter cherry } & 4.0 & 78.02 & \multirow{4}{*}{$55.22 \mathrm{ab}$} & 83.52 & \multirow{4}{*}{$63.73 \mathrm{a}$} \\
\hline & 2.0 & 61.54 & & 68.13 & \\
\hline & 1.0 & 47.25 & & 59.34 & \\
\hline & 0.5 & 34.07 & & 43.96 & \\
\hline \multirow{4}{*}{ Neem } & 4.0 & 69.23 & \multirow{4}{*}{$50.55 \mathrm{ab}$} & 75.82 & \multirow{4}{*}{$54.66 \mathrm{ab}$} \\
\hline & 2.0 & 57.14 & & 59.34 & \\
\hline & 1.0 & 45.05 & & 47.25 & \\
\hline & 0.5 & 30.77 & & 36.26 & \\
\hline \multirow{4}{*}{ Thorn apple } & 4.0 & 84.62 & \multirow{4}{*}{$59.34 \mathrm{a}$} & 85.71 & \multirow{4}{*}{$62.36 \mathrm{a}$} \\
\hline & 2.0 & 71.43 & & 65.93 & \\
\hline & 1.0 & 45.05 & & 58.24 & \\
\hline & 0.5 & 36.26 & & 39.56 & \\
\hline \multirow{4}{*}{ Common milkweed } & 4.0 & 53.85 & \multirow{4}{*}{$43.13 \mathrm{ab}$} & 49.45 & \multirow{4}{*}{$35.99 \mathrm{ab}$} \\
\hline & 2.0 & 51.65 & & 43.96 & \\
\hline & 1.0 & 35.16 & & 28.57 & \\
\hline & 0.5 & 31.87 & & 21.98 & \\
\hline \multirow{4}{*}{ Sweet clover } & 4.0 & 13.18 & \multirow{4}{*}{$8.24 \mathrm{~cd}$} & 46.15 & \multirow{4}{*}{$29.11 \mathrm{bc}$} \\
\hline & 2.0 & 9.89 & & 27.47 & \\
\hline & 1.0 & 7.69 & & 21.97 & \\
\hline & 0.5 & 2.19 & & 20.87 & \\
\hline \multirow{4}{*}{ Egyptian henbane } & 4.0 & 91.21 & \multirow{4}{*}{$64.84 \mathrm{a}$} & 73.63 & \multirow{4}{*}{$46.97 \mathrm{ab}$} \\
\hline & 2.0 & 75.82 & & 60.44 & \\
\hline & 1.0 & 56.04 & & 35.16 & \\
\hline & 0.5 & 36.26 & & 18.68 & \\
\hline
\end{tabular}

In columns, values followed by the same letter are not significancy differences at $5 \%$ level of probability.

\subsection{Effect of plant extracts on eggs of $T$. urticae in laboratory}

Only four plant extracts were used on eggs of $T$. urticae with $4 \%$ concentration Table (3). The inhibition rate on eggs caused by methanol plant extracts after 6 days were $(63.14,57.34,49.42$ and 
$39.71 \%$ ) for Egyptian henbane, winter cherry, thorn apple and neem respectively. While when extracted by acetone the inhibition rate was 61.40 ,
53.80, 49.12 and $46.20 \%$ for Winter cherry, thorn apple, Egyptian henbane and neem respectively. Statistically significant were found among treatments.

Table (3): Inhibition percentages of eggs of $T$. urticae mite after 6 days from spraying by (4\%) concentration of plant extracts extracted by Acetone and methanol solvent under laboratory conditions.

\begin{tabular}{|l|c|c|c|c|c|c|}
\hline \multirow{2}{*}{ Plant extracts } & \multicolumn{3}{|c|}{ Acetone } & \multicolumn{3}{c|}{ Methanol } \\
\cline { 2 - 7 } & $\begin{array}{c}\text { Mean n. of eggs } \\
\text { hatched } \pm \text { SE }\end{array}$ & $\begin{array}{c}\text { Hatchability } \\
(\%)\end{array}$ & $\begin{array}{c}\text { Inhibition } \\
(\%)\end{array}$ & $\begin{array}{c}\text { Mean n. of eggs } \\
\text { hatched } \pm \text { SE }\end{array}$ & $\begin{array}{c}\text { Hatchability } \\
(\%)\end{array}$ & $\begin{array}{c}\text { Inhibition } \\
(\%)\end{array}$ \\
\hline Winter cherry & $13.20 \pm 1.11$ & 33 & $61.40 \mathrm{ab}$ & $15.60 \pm 1.69$ & 39.00 & $57.34 \mathrm{c}$ \\
\hline Neem & $18.40 \pm 0.74$ & 46 & $46.20 \mathrm{ef}$ & $21.80 \pm 1.49$ & 54.50 & $39.71 \mathrm{~g}$ \\
\hline Thorn apple & $15.80 \pm 1.49$ & 39.50 & $53.80 \mathrm{~cd}$ & $18.40 \pm 1.43$ & 46.00 & $49.42 \mathrm{de}$ \\
\hline Egyptian henbane & $17.40 \pm 1.77$ & 43.50 & $49.12 \mathrm{de}$ & $13.60 \pm 1.20$ & 34.00 & $63.14 \mathrm{a}$ \\
\hline Control & $35.80 \pm 0.83$ & 89.50 & - & - & - & - \\
\hline
\end{tabular}

Data are presented as mean value \pm SE. $a, b$ Different letters indicate a significant difference according to Duncan's multiple range tests. Values are significant at $\mathrm{p}=0.05$ levels, $\mathrm{df}=44, \mathrm{~F}$-value $=44.35$ (after 6 days).

\subsection{Effect of plant extracts on population} of T. urticae infested Kidney bean under field conditions

The effect of the four plant extracts obtained from Winter cherry, Neem, Thorn apple and Egyptian henbane against $T$. urticae population on Kidney bean field conditions were summarized in Table (4). The results so close with those obtained from the laboratory experimental. When the plant extracts applied at $4 \%$ concentration at the field on Kidney bean crop when used methanol solvent, Thorn apple recorded higher reduction percentages within $80.53,80.30,92.24,78.38$ and $65.90 \%$ reduction and average of reduction was
79.47\% after 1, 3, 7, 14 and 21days, respectively. While Winter cherry extract recorded $71.20,64.72,79.29,81.28$ and $76.61 \%$ reduction percentages after 1,3 , 7, 14 and 21 days with average $74.62 \%$. While the third place was plant extract of Egyptian henbane with reduction percentages $74.00,66.22,72.51,80.57$ and $62.53 \%$ after $1,3,7,14$ and 21 days with average $70.34 \%$. The Neem plant extract was the least effective one for reduction of $T$. urticae with reduction percentages $68.89,63.91,78.20,69.76$ and $59.02 \%$ after one day, three days, one week, two weeks and three weeks with average $67.95 \%$. Statistical analysis showed significant difference among the treatments. 
Table (4): Mean and reduction percentages of spider mite populations by using different plant extracts on Kidney bean at concentration $4 \%$ under the field conditions.

\begin{tabular}{|c|c|c|c|c|c|c|c|}
\hline \multirow{2}{*}{ Treatments } & \multirow{2}{*}{ Means } & \multicolumn{6}{|c|}{ Reduction of the spider mite population with days (\%) } \\
\hline & & $1 \mathrm{st}$ & 3rd & 7th & 14th & 21st & Average \\
\hline \multirow{2}{*}{ Winter cherry } & $\mathrm{M}$ & 9.2 & 7.7 & 6.1 & 5.7 & 7.4 & 7.22 \\
\hline & $\mathrm{R} \%$ & 71.20 & 64.72 & 79.29 & 81.28 & 76.61 & $74.62 \mathrm{ab}$ \\
\hline \multirow{2}{*}{ Neem } & $\mathrm{M}$ & 8.2 & 6.5 & 5.3 & 7.6 & 10.7 & 7.66 \\
\hline & $\mathrm{R} \%$ & 68.89 & 63.91 & 78.20 & 69.76 & 59.02 & $67.95 \mathrm{bc}$ \\
\hline \multirow{2}{*}{ Thorn apple } & $\mathrm{M}$ & 6.8 & 4.7 & 2.5 & 7.2 & 11.8 & 6.60 \\
\hline & $\mathrm{R} \%$ & 80.53 & 80.30 & 92.24 & 78.38 & 65.90 & $79.47 \mathrm{a}$ \\
\hline \multirow{2}{*}{ Egyptian henbane } & $\mathrm{M}$ & 8.00 & 7.10 & 7.80 & 6.80 & 11.30 & 8.20 \\
\hline & $\% \mathrm{R}$ & 74.00 & 66.22 & 72.51 & 80.57 & 62.53 & $70.34 \mathrm{ab}$ \\
\hline Control & M & 32.2 & 22 & 29.7 & 30.7 & 31.9 & 29.30 \\
\hline
\end{tabular}

Different letters indicate a significant difference between the mean according to Duncan's multiple range tests. Values are significant at $\mathrm{p}=0.05$ levels, $\mathrm{df}=19, \mathrm{~F}$-value $=2.08$.

\subsection{Effect of plant extracts on population} of $T$. urticae infested cucumber under field condition

The effect of four plant extracts at $4 \%$ concentration against mites, T. urticae showed reduction in mite's infestation on cucumber under field conditions (Table 5). Egyptian henbane was found potent extract against the two-spotted spider mite it caused 69.63, 83.89, 86.76, 78.83 and $81.70 \%$ reduction percentages after
$1,3,7,14$ and 21 days respectively, with average $80.16 \%$. While neem extract recorded $70.38,69.31,80.45,81.21$ and $79.05 \%$ reduction percentages after the same periods respectively, with average $76.01 \%$. But winter cherry and thorn apple extracts give converged reduction rate that is almost the same were 68.12 , $76.19,72.36,77.30$ and $80.41 \%$ and $70.38,63.18,87.00,82.72$ and $69.27 \%$ after $1,3,7,14$ and 21 days respectively with average 74.88 and $74.51 \%$.

Table (5): Mean and reduction percentages of spider mite by using different plant extracts on cucumber at the field condition.

\begin{tabular}{|l|l|l|l|l|l|l|l|}
\hline \multirow{2}{*}{ Treatments } & \multirow{2}{*}{ Means } & \multicolumn{5}{|c|}{ Reduction of the spider mite population with days (\%) } \\
\cline { 3 - 8 } & & lst & 3rd & 7th & 14th & 21st & Average \\
\hline \multirow{3}{*}{ Winter cherry } & $\mathrm{M}$ & 11.60 & 9.80 & 13.60 & 12.60 & 11.70 & 11.86 \\
\cline { 2 - 8 } \multirow{2}{*}{ Neem } & $\mathrm{R} \%$ & 68.12 & 76.19 & 72.36 & 77.30 & 80.41 & $74.88 \mathrm{ab}$ \\
\hline \multirow{2}{*}{ Thorn apple } & $\mathrm{M}$ & 9.40 & 10.90 & 8.30 & 9.00 & 10.80 & 9.68 \\
& $\mathrm{R} \%$ & 70.06 & 69.31 & 80.45 & 81.21 & 79.05 & $76.01 \mathrm{ab}$ \\
\hline \multirow{2}{*}{ Egyptian henbane } & $\mathrm{M}$ & 9.10 & 12.80 & 5.40 & 8.10 & 15.50 & 10.18 \\
\cline { 2 - 9 } & $\mathrm{R} \%$ & 70.38 & 63.18 & 87.00 & 82.72 & 69.27 & $74.51 \mathrm{ab}$ \\
\hline Control & $\mathrm{M}$ & 9.50 & 5.70 & 5.60 & 10.10 & 9.40 & 8.06 \\
\cline { 2 - 8 } & $\mathrm{R} \%$ & 69.63 & 83.89 & 86.76 & 78.83 & 81.70 & $80.16 \mathrm{a}$ \\
\hline
\end{tabular}

Values by the same letter are not s significant at $\mathrm{p}=0.05$ levels, $\mathrm{df}=19, \mathrm{~F}$-value $=0.677$.

\section{Discussion}

Based on present study, the plant extracts which extracted from winter cherry
(Withania

somnifera),

(Azadirachta indica), thorn apple (Datura stramonium) and Egyptian henbane (Hyoscyamus muticus) are 
promising for the control of T. urticae and both of acetone and methanol were favorable to plant extraction. The present results of neem extract are in agreement with those documented by Mansour et al. (1997) they evaluated neemgard, an acaricidal formulation obtained from Neem (Azadirachta indica) on the phytophagous mite Tetranychus Cinnabarinus, predacious mite Phytoseiulus persimilis, and the predatory true spider Chiracanthium mildei, were investigated in laboratory. They found neemgard was highly toxic to $T$. cinnabarinus. In addition, Kumral et al. (2010) demonstrated that, leaf and seed extracts of Datura stramonium had lethal effects on $T$. urticae. The death rate for females exposed to leaf extract was between 29 and $98 \%$ after $48 \mathrm{~h}$. The same conclusion was found by Mateeva et al. (2003). When $D$. stramonium extracts was used for their acaricidal activity against $T$. urticae under laboratory conditions, the compound was toxic to all active stages of the spider mite. Moreover, some studies showed that certain alkaloids are present in different amounts in different parts of Datura spp., thereby possibly explaining why leaf extracts effective in our studies (Anonymous, 2008; Berkov et al., 2006; Philipov and Berkov, 2002). Also, this result agreement with Abu Shosha (2020), found that, Datura stramonium leaves, Egyptian henbane Hyoscoyamus muticus flowers extracted by acetone solvent had effect on $\mathrm{T}$. urticae when applied on eggplant crop Solanum molongena and kidney bean crop Phasolus vulgaris at concentration $4 \%$ the reduction percentages of mite populations were determined after 1, 3, 7, 14 and 21 days from treatments. Mortalities percentages were 92.30 and $94.12 \%$ on eggplant and kidney bean respectively. Finally, the plant extracts of A. indica, $H$. muticus, D. stramonium and $W$. somnifera can be introduced as alternative to conventional synthetic acaricides against $T$. urticae mite.

\section{References}

Abbott, W. S. (1925), "A method of computing the effectiveness of an insecticide", Journal of Economic Entomology, Vol. 18, pp. 265-267.

Anonymous (2008), "Tropane alkaloids (from Datura sp.) as undesirable substances in animal feed scientific opinion of the panel on contaminants in the food chain", EFSA Journal, Vol. 691, pp. 1-55.

Abou-Shosha, M. A. A. (2020), "Field trial of three plant extracts against Tetranychus urticae population as a comparative with acaricidal (Abamectin) on two vegetable crops", Journal of Plant Protection and Pathology, Vol. 11 No. 9, pp. 473-476.

Berkov S., Zayed, R., Doncheva, T. (2006), "Alkaloid patterns in some varieties of Datura stramonium", Fitoterapia, Vol. 77, pp. 179-182.

Cremlyn, R. (1978), Pesticides, 
preparation and mode of action, $\mathrm{J}$. Wiley and Sons, New York, USA, pp. 39-49.

Chakraborty, A., Singh, M. and Ridland, P. (2009), "Effect of preytaxis on biological control of the two-spotted spider mite - A numerical approach", Mathematical and Computer Modelling, Vol. 50(34), pp. 598-610.

Fasulo, T. R. and Denmark, H. A. (2000), Two spotted spider mite, Tetranychus urticae Koch (Arachnida: Acari: Tetranychidae), Entomology and Nematology Department publication No. EENY150, Florida Cooperative Extension Service, Institute of Food and Agricultural Sciences, University of Florida, USA.

Guo, F., Zhi-Qiang, Z. and Zhimo, Z. (1998), "Pesticide resistance of Tetranychus cinnabarinus (Aacri: Tetranychidae) in China: a review", Systematic \& Applied Acarology, Vol. 3, pp. 3-7.

Hikal, W. M., Baeshen, R. S. and SaidAl Ahl, H. A. (2017), "Botanical insecticide as simple extractives for pest control", Cogent Biology, Vol. 3 No. 1, pp. 140-427.

Jeppson, L. R., Keifer, H. H. and Baker, E. W. (1975), Mites injurious to economic plants, University of California Press, Barkely, USA, pp. 614.

Kumral, N. A., Çobanoğlu, S. and
Yalcin, C. (2010), "Acaricidal, repellent and oviposition deterrent activities of Datura stramonium L. against adult Tetranychus urticae (Koch)", Journal of Pest Science, Vol. 83, pp. 173-180.

Kapsoot, E., Mwangi, M. and Kamau, A. (2013), Repellence and toxicity effect of crude plant extracts on the two-spotted spider mite Tetranychus urticae on roses, In: I International Symposium on Ornamentals in Africa, pp. 155164.

Mansour, F. A., Ascher, K. R. S. and Abo-Moch, F. (1997), "Effects of neemgard on phytophagous and predacious mites and on spiders", Phytoparasitica, Vol. 25 No. 4, pp. 333-336.

Mateeva, A. A., Christov, C., Stratieva, S. and Palagatscheva, N. (2003), Alternative plant protection means against Tetranychus urticae Koch, Mitteilungen aus der Biologischen Bundesanstalt für Land- und Forstwirtschaft, Berlin, Germany, 259-261.

Norval, R. A. I., Perry, B. D. and Young, A. S. (1992), The epidemiology of the ileriosis in Africa, Academic Press, London, UK, pp. 301-342.

Philipov, S. and Berkov, S. (2002), "GCMS investigation of tropane alkaloids in Datura stramonium", Z. Naturforsch, Vol. 57c, pp. 559-561.

Rabbinge, R. (1985), "Aspects of damage 
Mahmoud et al. / Archives of Agriculture Sciences Journal 4(2) 61-70, 2021.

assessment", In Spider mites: their biology, natural enemies and control, Vol (1B), Elsevier Science Publishers BV, Amsterdam, Netherlands, pp. 261-272. 